\title{
Erratum to: Gamma band activity in the RAS-intracellular mechanisms
}

\author{
E. Garcia-Rill $\cdot$ N. Kezunovic $\cdot$ S. D'Onofrio $\cdot$ \\ B. Luster $\cdot$ J. Hyde $\cdot$ V. Bisagno $\cdot$ F. J. Urbano
}

Published online: 31 January 2014

(C) Springer-Verlag Berlin Heidelberg 2013

\section{Erratum to: Exp Brain Res}

\section{DOI 10.1007/s00221-013-3794-8}

In the original publication, the reference Simor et al. (2013) was inadvertently miscited; the wrong journal was given in the reference.

The correct reference should read as follows:

\section{Reference}

Simor P, Horvath K, Ujma PP, Gombos F, Bodizs R (2013) Fluctuations between sleep and wakefulness: wake-like features indicated by increased EEG alpha power during different stages in nightmare disorder. Biol Psychol 94:592-600

\footnotetext{
The online version of the original article can be found under doi:10.1007/s00221-013-3794-8.

E. Garcia-Rill $(\bowtie) \cdot$ N. Kezunovic · S. D'Onofrio · B. Luster · J. Hyde Department of Neurobiology and Developmental Sciences, Center for Translational Neuroscience, University of Arkansas for Medical Sciences, Slot 847, 4301 West Markham St., Little Rock, AR 72205, USA

e-mail: GarciaRillEdgar@uams.edu

V. Bisagno $\cdot$ F. J. Urbano

IFIBYNE, CONICET-UBA, Buenos Aires, Argentina

V. Bisagno $\cdot$ F. J. Urbano

ININFA, CONICET-UBA, Buenos Aires, Argentina
} 